\title{
A NALISES DE LIVROS
}

\author{
DILEMMAS IN MANAGEMENT OF THE NEUROLOGICAL PATIENT. C. WARLOW \\ \& J. GARFIELD, editores. Um volume $(\mathbf{1 5 , 5 \times 2 4 )}$ encadernado, com 285 páginas, \\ 36 tabelas e 18 figuras. Churchill Livingstone, 1984.
}

Questões controversas e opiniões divergentes pontilham a Neurologia e a Neurocirurgia, sobretudo no que concerne a atitudes terapêuticas. O dilema entre a intervenção cirúrgica e a terapêutica conservadora, ou a escolha de processos de tratamento clínico ou ainda a técnica cirúrgica a ser adotada, são, em determinadas circunstâncias, matérias de dúvidas entre os especialistas.

Neste livro, seus organizadores solicitaram aos colaboradores, todos eles britânicos, a revisão de áreas controversas que frequentemente embaraçam o clínico ao assumir uma atitude terapêutica, clínica ou cirúrgica. São 26 temas, todos de interesse. Dentre eles, mencionamos apenas alguns que exemplificam o interesse desta publicação. Tema 2: “A manipulação do sistema imunológico é útil na esclerose múltipla?” Hughes, seu autor, friza o paradoxo de atitudes antagônicas, visando à imunossupressão ou pelo contrário, à imunoestimulação. Friza, no entanto, as bases científicas em que repousam essas medidas terapêuticas. Tema 4: “Os anticoagulantes previnem o embolismo do coração para o cérebro?” (D. de Boni). O advento da tomografia computadorizada trouxe para a Clínica um dilema até então dificilmente existente: "Devem os hematomas cerebrais espontâneos ser evacuados e no caso positivo, quando?" Marshall demonstra que essas indicações devem ser muito bem ponderadas e que uma precipitada intervenção neurocirúrgica deve ser evitada. Com efeito, tomografias seriadas demonstram sua frequente resolução espontânea. A sede dos hematomas é também fator importante, pois diferente é seu risco. Assim, os hematomas cerebelares devem ser considerados separadamente em relação aos hematomas suipratentoriais. Não são excepcionais, pois constituem cerca de 5 a $10 \%$ de todos os hematomas intracranianos e sua gravidade reside sobretudo nas possíveis compressões do tronco do encéfalo que aumentam sensivelmente a mortalidade. Nesses casos, apesar da alta mortalidade em pacientes comatosos, lima atitude cirúrgica ainda é justificada pois, caso contrário, o prognóstico é sempre fechado. Além disso, os sobreviventes à remoção cirúrgica dos hematomas cerebelares muito frequentemente irão sofrer sequelas importantes. $O$ tema 6 (Harrison) é constituído também de uma pergunta. "H o "enxugar" (shrinking) uma boa coisa do encéfalo após um enfarte cerebral?" Após considerações físiopatológicas e o estudo das diferentes terapêuticas, o autor conclui que a indicação da osmoterapia é, na melhor das hipóteses, de eficácia não comprovada, seja por ser realmente ineficiente, seja porque os casos não foram ainda bastante numerosos para demonstrar alguma utilidade. Medidas do fluxo cerebral e da pressão do LCR, 36 horas após o enfarto, demonstram que o tratamento pelo glicerol pode reduzir a pressão do LCR e aumentar o fluxo cerebral. Dos temas, salientam-se ainda: “W o L-dopa prejudicial?" (Lees), “Qliando suspender as drogas anticonvulsivantes?” (D. Chaduvick), “O que é a cefaléia após punção lombar e é ela evitável?" (Hilton-Jones), "Hidrocefalia sob pressão normal, derivar ou não?" (Pickard), "Convulsões febris na infância, são necessáários anticonvulsivantes profiláticos?" (N. Gordon). Esses exemplos comprovam a utilidade deste livro, baseado em literatura bem escalhida e na experiência pessoal dos autores. 
LAQUIDO CEFALORRAQUIDEO. D. DOMMASCH \& H. G. MERTENS, editores. Um volume (18x25) encadernado, com 304 páginas, 36 tabelas e 79 figuras. Versão espa. nhola de J. Odrizola Lino. Toray, Barcelona, 1983.

Para aqueles que se dedicam ao estudo do líquido cefalorraqueano (LCR) um novo livro traduzido para o espanhol da edição alemã de 1980 está a venda. Esta é uma monografia coordenada por Dommasch e Mertens contando com a colaboração de 81 pesquisadores na maioria ligados a escolas da Alemanha. $O$ livro tem o sub-título de: citologia do LCR, patologia das zonas limítrofes, química do LCR, barreira hêmato-encefálica, farmacoterapia e transtornos circulatórios do LCR. O material está distribuido em 7 capítulos, cada um deles escrito por vários especialistas que se dedicam ao assunto e com grande quantidade de referencias bibliograficas atualizadas no final de cada um. O primeiro capítulo é introdução geral ao diagnóstico do LCR escrito em colaboração por um dos editores em que apresentam um resumo da importancia do estudo do LCR inclusive com protocalos de resultados de exame de grande valor prático. O segundo é dedicado ao estudo da citologia do LCR contando com a colaboração de renomados estudiosos do assunto, como A. Guseo, M. Oemichen e H. W. Kölmel, todos com obras próprias já publicadas. São discutidos aspectos do estudo citomorfológico do LCR, inclusive com novas técnicas de colaboração e abundante material fotográfico. Segue-se o estudo da estrutura das superficies limítrofes, com estudo histopatológico do epêndima e do sistema ventrícular e suas relações com o restante do sistema nervoso central. O quarto capítulo é reservado ao estudo químico do LCR com ênfase ao estudo proteico e de imunoglobulinas, com aspectos técnicos atuais e também com material fotográfico de ótima qualidade. O quinto capitulo é dedicado ao estudo virológico e bacteriológico do LCR com discussões a respeito da grande problemática do diagnóstico virológico do LCR e apresentando uma classificação destes agentes. Novas técnicas atuais com pesquisas de antígenos e anticorpos microbianos também são apresentadas. No estudo da farmacoterapia e barreira hêmato-encefálica são apresentados dados da cinética da barreira, com ênfase à introdução de medicamentos com suas respectivas concentrações, salientando-se as indicações de aplicação intratecal de antibióticos, citostáticos e glicocorticóides, constitut o material do sexto capítulo. O livro termina com capítulo sobre estudos de transtornos da circulação do LCR, a assim chamada terceira circulação, reunindo técnicas como monitorização de pressão, cintilografia, e fazendo paralelo com estudos tomográficos.

Somente pela enumeração do conteúdo é fácil deduzir que este é um livro obrigatório não só para aqueles que se dedicam ao estudo do LCR como também para todos aqueles que integram a Neurologia.

JOSE ANTONIO LIVRAMENTO

EVOKED POTENTIALS IN CLINICAL MEDICINE. KEITH H. CHIAPPA. Um volume (16x24) encadernado, com 340 páginas, 30 tabelas e 100 figuras. Raven Press, New York, 1983.

Assistimos na última década à emergência dos potenciais evocados, em três principais modalidades: visual por padrão reverso, auditivo (tronco cerebral) e sômato-sensitivo de curta latência. De modo cada vez mais abrangente, esses potenciais evocados vêm sendo usados como uma sequiência do exame neurológico (inclúdos as o neuro-oftalmológico e o neuro-otológico) pois, podem de forma não invasiva: 1) mostrar alterações em um sistema sensorial quando o exame clínico for inconclusivo; 2) mostrar a presença de distúrbios subclínicos em uma via sensorial; 3) servir à avaliação neurofisiológica no estudo de doenças; 4) monitorizar o paciente.

Nestas 340 páginas, que podemos considerar como um livro de texto atualizado sobre potenciais evocados, o autor executou um grande trabalho para sistematizar o 
tema de modo claro e didático, procurando fugir à confusão reinante na literatura, onde chegam a existir quase tantas técnicas quanto serviços trabalhando; embora as diferenças técnicas sejam frequentemente pequenas, talvez por essa mesma razão, não é fácil conciliá-las. Nesse sentido, o autor utiliza como principal referência o laboratório de Neurofisiologia Clínica do Massachusetts General Hospital, com uma casuística seguramente respeitável (acima de 3000 pacientes examinados em cada modalídade de potencial evocado). No primeiro capítulo, o autor introduz o tema, discutindo os princípios básicos dos potenciais evocados, além do equipamento e da nomenclatura. A seguir, em mais 6 capítulos, e dedicando dois a cada uma das três modalídades, o autor discute separadamente metodologia e interpretação dos potenciais evocados. Na metodologia, além do modo de obtenção, são descritos os dados normativos e os fatores não patológicos que influenciam os valores obtidos no exame dos potenciais evocados. $\mathrm{Na}$ interpretação, para cada um dos potenciais evocados discutem-se os geradores, a fisiopatologia voltada para a análise clínica, e por fim os aspectos clínicos, onde são analisados os achados em grande número de doenças.

\section{F. J. CARCHEDI LUCCAS}

BIOLOGICAL RHYTHMS AND BEHAVIOR. J. MENDLEWICZ \& H. M. VAN PRAAG, editores. Um volume (16x22) encadernado, com 149 páginas, 50 figuras e 16 tabelas. Volume 11 da série Advances in Biological Psychiatry. Karger, Basel, 1983.

O ritmo circadiano é visto nesta obra como um conjunto de variáveis fisiológicas e psicológicas, sincronizadas nas 24 horas do dia, e com características endógenas. Trabalhos experimentais e textos expositivos foram aqui unidos formando uma amostra da larga gama de aspectos que compõe este tema.

Goos, do National Institute of Mental Health, em Bethesda, EUA, descreve o conceito de periodicidade temporal e seu substrato biológico. $O$ sistema neuroendócrino surge como determinante destas oscilações que afetam o comportamento a sintese proteica cerebral. Os efeitos de drogas psicoativas sobre tais "relógios biológicos" são também descritos. O tema avança, mostrando a reação humana às mudanças bruscas da regularidade do binômio vigilia-sono, verificada tanto nas alterações de turnos de trabalhos como as ocasionadas pela passagem de vários fusos horários em viagens aéreas a longas distâncias. Os aspectos patológicos são avaliados mostrando as alterações do sono que ocorrem em pacientes com desordens afetivas e insônia. Merece atenção especial o intrigante texto em que Kalverboer expõe a organização da periodicidade comportamental em lactentes, investiga seu papel como indicador de interação com o ambiente social e extrapola suas possíveis relações psicopatológicas.

RUBENS REIMAO

MATHEMATICAL MODELS OF THE CIRCADIAN SLEEP-WAKE CYCLE. $M . C$. MOORE-EDE \& C. A. CZEISLER, editores. Um volume $(16 \times 22,5)$ encadernado, com 216 páginas, 97 figuras e uma tabela. Raven Press, New York, 1984.

Há pouco mais de dez anos, o núcleo supraquiasmático do hipotálamo foi descrito como marcapasso essencial no controle do ritmo circadiano dos mamíferos. Desde então, muito se pesquisou neste campo e vários conceitos inovadores surgiram. Ficou claro que não existe um único relógio controlador de nossos ritmos mas uma rede complexa de osciladores, em vários tecidos, e unidos por vias neurais e endócrinas. Assim, como exemplo, a secreção do hormônio de crescimento varia de maneira regular durante as 24 horas do dia, a temperatura corpórea também o faz desta forma e o comportamento vigília-sono segue o mesmo padrão, mostrando a intrincada união entre 
fenômenos a primeira vista tão distintos. Caso se coloque um indivíduo em ambiente desprovido de qualquer evidência da passagem do tempo (como relógios ou luz) a organização persiste de maneira coerente. O desejo de compreensão destas modificações fisiológicas regulares levou à procura da aplicação do conceito matemático de sistema de múltiplos osciladores e deu origem a este apaixonante campo de estudos.

Este é um dos primeiros livros dedicados ao tema da matemática aplicada ao ritmo circadiano e é certamente o único que uniu pesquisadores de diferentes escolas, analisando de forma crítica os vários conceitos e modelos. Abrange tanto a revisão das diferentes teorias como as hipóteses mais recentes, tornando sua leitura recomendável a todos os que, nas disciplinas do sistema nervoso, se dedicam ao estudo da deflagração e manutenção do ritmo vigília-sono. 